\title{
Some etiopathogenetic features of dogs' breast tumors
}

\author{
Nikolay Krasnoslobodtsev ${ }^{1, *}$, Evgeny Shapiro ${ }^{1}$, Tatyana Alymova ${ }^{2}$, \\ and Natalya Kuharenko ${ }^{3}$ \\ ${ }^{1}$ Veterinary Clinic «Druzhok», Jambula 34 st. office 1, Khabarovsk, Khabarovsk Territory, Russian \\ Federation, 680011 \\ 2“"Kobets" FE, Veterinary Center «Beethoven», Khabarovsk, Russia \\ ${ }^{3}$ Far Eastern State Agrarian University ,86, Politeknicheskaya Str., Blagoveschensk, Russia
}

\begin{abstract}
The article presents data on the epidemiological features of breast cancer in dogs, namely: the frequency of oncological pathologies in dogs in 2017-2019, the structure of oncological diseases, studied the agesex characteristics of breast tumors, the frequency of certain risk factors leading to the development of breast neoplasms in dogs. From this study, it was found that neoplasms occurred in $4.8 \%$ of the dogs admitted to the clinic. In dogs, a mammary gland tumor was recorded in 153 individuals of which, 150 females and 3 males. Breast tumors ranked first in localization ( $28 \%$ of all tumors), and skin tumors ranked second ( $8.5 \%$ of all tumors). In females, the first place is a breast tumor (45\%), in males - skin tumors $(13 \%)$. In most animals, the size of a breast tumor at its primary detection corresponded to the T2-T4 stage according to the TNM classification, and in some cases T4a-d. Out of 150 females with breast tumors, only 40 were castrated. This justifies the need for the formation of approaches to early diagnosis of breast tumors in domestic dogs, as well as to the study and prevention of risk factors.
\end{abstract}

\section{Introduction}

Currently, more and more often in the practice of a veterinarian there are patients with breast tumors, and the relevance of work in the direction of studying this pathology is determined by several factors. The first factor is the economic damage in agriculture, which can reach large scales; it was he who required the development of appropriate measures, which were to be based on scientific research. The second factor is the interest in comparing tumors of domestic animals and humans, since the study of mammary gland tumors in dogs as a "model" played a large role in the formation of knowledge about the essence of the tumor process [12]. The third factor is widespread urbanization and a large number of pets that live in cities near a person, which in turn leads to caring for "our smaller brothers". Since a breast tumor is one of the most common oncological pathologies,

${ }^{*}$ Corresponding author: Nikola-kila@mail.ru 
more and more specialists in the treatment of these diseases appear in modern veterinary clinics.

Interest in studying various aspects of cancer pathology in small domestic animals is constantly growing. This is due to the emergence of a real possibility of increasing the duration and quality of animals' life with cancer. At the same time, epidemiological studies, in comparison with other issues being studied, are extremely rare.

So, according to some foreign and Russian studies, one of the most common types of tumors in dogs are breast tumors [1,2,3]. However, it should be noted that on a number of aspects, some data are contradictory or insufficient. There are contradictory data on the relationship of reproductive status with the development of breast tumors, on the breed predisposition to the oncological process, there is little information about the role of the conditions of keeping animals, and there are practically no data on the state of immunity.

The most studied is the question of the structure of the identified neoplasms. So, according to Yakunina M.N. and a number of other authors, cats most often have lymphomas and skin tumors, and breast tumors are in third place, while dogs have breast tumors in second place after skin tumors. It is also known from this source that in castrated female dogs before the first estrus, breast tumors are much less common [1, 3, 4].

It should be emphasized that it is epidemiological studies that allow us to establish the relationship between tumors and various causative factors, including environmental ones, to identify risk groups, to study the structure of the pathology, its age-gender and breed characteristics.

\subsection{The aims and objectives of the study}

The main goals and objectives of this study is to study the example of 549 dogs admitted to the Druzhok veterinary clinic:

1. The frequency of cancer pathologies in dogs

2. The structure of oncological pathologies in dogs

3. Investigate age-sex characteristics of breast neoplasms

4. The frequency of selected risk factors in dogs.

\section{Materials and research methods}

The study included all dogs that were admitted to the multidisciplinary veterinary clinic «Druzhok» (Khabarovsk) in 2017-2019.

A total of 11575 dogs contacted the reception. Among them, 549 animals with neoplasms were identified (4.8\%). For the diagnosis of neoplasms, in accordance with modern requirements [1, 2], clinical examination data, results of X-ray, ultrasound, endoscopy, laboratory and morphological examinations were used.

$\mathrm{X}$-ray research was performed on a digital X-ray apparatus, ultrasound on an ultrasound apparatus of the expert class Mindray DC-8, endoscopic examination using the Karl Storz TELE PACK VET video system, laboratory tests (general, biochemical blood analysis) using automatic biochemical and hematological analyzers manufactured by Mindray. Material for morphological research was sent to the laboratory of Dr. Mitrokhina (Moscow). 


\section{Results and discussion}

Neoplasms of all types (benign, malignant and unknown) with different localization were detected in 549 dogs out of 11575 admitted to the Druzhok veterinary clinic both for treatment and for various examinations and for various planned manipulations, including vaccination. Accordingly, $4.8 \%$ of dogs have various neoplasms. Thus, we have found that tumor processes are quite common and require close attention from veterinarians.

Table 1. The frequency of detection of neoplasms of dogs, depending on the sex of the animal.

\begin{tabular}{|c|c|c|c|c|c|c|c|c|c|}
\hline \multirow{2}{*}{$\begin{array}{c}\text { Species } \\
\text { and gender } \\
\text { of animal }\end{array}$} & \multicolumn{2}{|c|}{$\begin{array}{c}\text { Total number of animals } \\
\text { admitted to the clinic }\end{array}$} & \multicolumn{4}{|c|}{$\begin{array}{c}\text { Number of animals } \\
\text { diagnosed with } \\
\text { neoplasms }\end{array}$} & \multicolumn{4}{|c|}{$\begin{array}{c}\text { The frequency of } \\
\text { detection of } \\
\text { neoplasms (\%) }\end{array}$} \\
\cline { 2 - 11 } & $\mathrm{M}$ & $\mathrm{F}$ & Total & $\mathrm{M}$ & $\mathrm{F}$ & Total & $\mathrm{M}$ & $\mathrm{F}$ & Total \\
\hline Dogs & 6267 & 5308 & 11575 & 220 & 329 & 549 & $3.5 \%$ & $6.1 \%$ & $4.8 \%$ \\
\hline
\end{tabular}

Table 1 shows that the frequency of all neoplasms in female dogs was $6.1 \%$, while in males $-3.5 \%$, and this allows us to conclude that females are more susceptible to the oncological process. Perhaps this is due to the presence of a target organ - the mammary gland.

When studying the structure of detected neoplasms in dogs by localization, it turned out that among all neoplasms in general, breast neoplasms are most common - $28 \%$, then skin tumors $-8.5 \%$, gastrointestinal tumors $-5.8 \%$, tumors of the lymphatic system $-4.2 \%$. Tumors at other sites are less common in dogs (Figure 1).

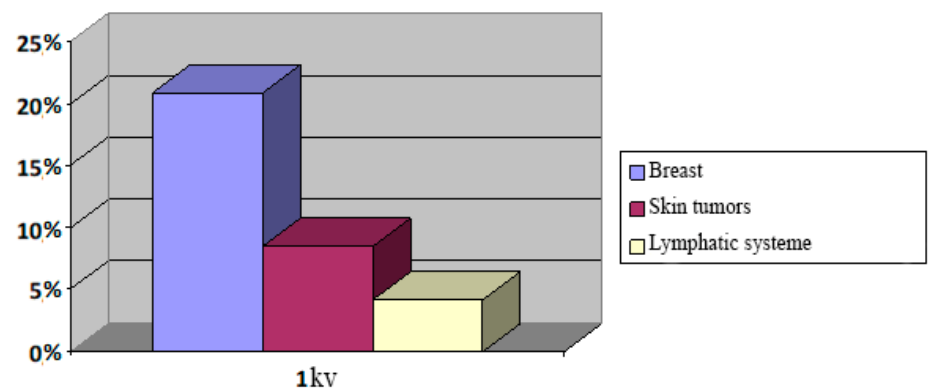

Fig. 1. Tumors at other sites are less common in dogs.

When conducting an analysis to identify sexual predisposition among all dogs with oncological processes, the following results were obtained.

In females, breast tumors are in the first place $-45 \%$, skin tumors $-5.4 \%$, the third place is the neoplasm of the gastrointestinal tract $-2.5 \%$, the fourth - the lymphatic system $3 \%$, followed by neoplasms of the respiratory system (Fig. 2).

Thus, we can say that breast tumors in female dogs are much more common than other oncological pathologies. 


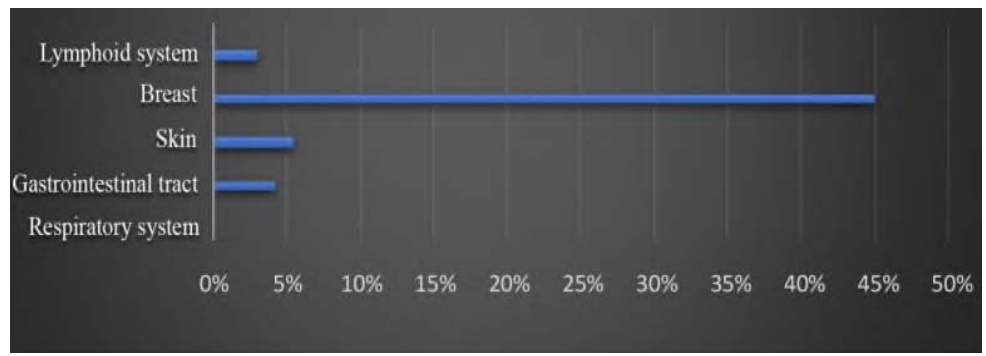

Fig. 2. The structure of neoplasms of dogs (females) by localization.

The males were dominated by skin neoplasms - $13.1 \%$, then the gastrointestinal tract $8.1 \%$, in the third place is the organs of the lymphatic system $-5.9 \%$, the OMF $-1.3 \%$, and the fifth place is the respiratory organs $-0.9 \%$ (Fig. 3)

Picture 2

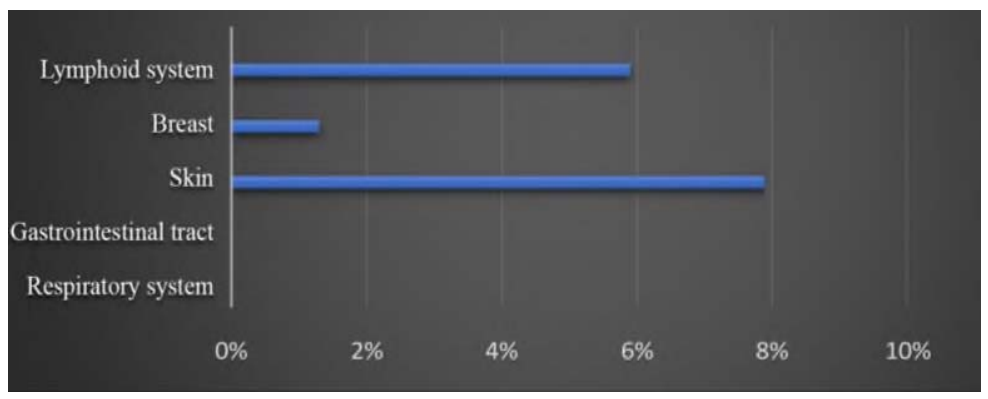

Fig. 3. The structure of neoplasms of dogs (males) by localization.

To develop approaches to early diagnosis of the most common neoplasms, an in-depth analysis of breast neoplasms was carried out, which accounted for the largest number of cases detected.

Analysis of the incidence of breast tumors in different age groups revealed the following features (Fig. 4).

Neoplasms can begin to form at a young age from 4 to 6 years. The proportion of animals in which they are present at this age is $3 \%$ of the total number of dogs with breast cancer. At the age of 7 to 11 years, the proportion of animals with breast tumors increases many times and amounts to $27 \%$. Further, the indicator grows exponentially. In animals aged 11 to 15 years, breast neoplasms in $56 \%$ of cases were the cause of treatment. Older than 16 years, this indicator is $14 \%$.

Thus, it is necessary to take into account the age of the patient during the examination, from this study it can be concluded that from the age of 7 in dogs, increased attention should be paid to the mammary gland during examination [8].

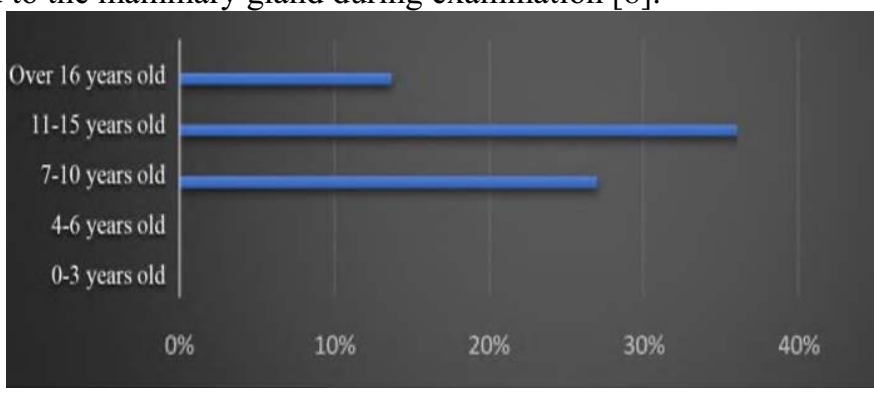

Fig. 4. The frequency of breast tumors of dogs in different age groups. 
In conducting our research, we also examined risk factors. Among the risk factors for breast cancer in animals, including dogs, hormonal contraception, false pregnancy, prolonged estrus or its absence are well studied [6,8]. Of the 153 animals with mammary gland tumors, 40 dogs $(26 \%)$ were neutered. The fact at what age the animals were castrated was not taken into account (Fig. 5.). It follows from this that non-castrated animals are more prone to breast tumors [9].

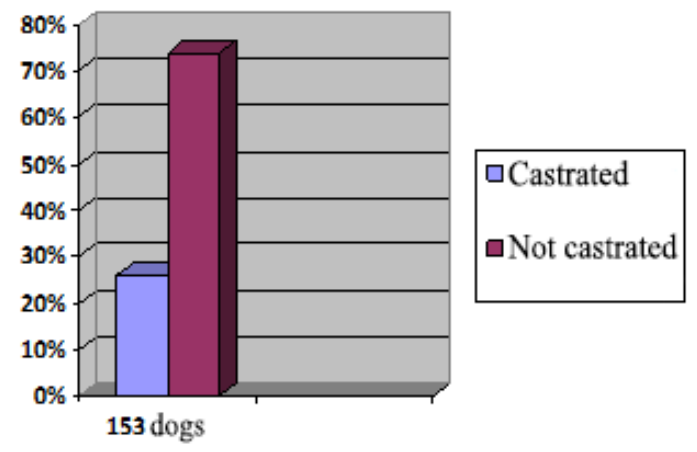

Fig. 5. The fact at what age the animals were castrated was not taken into account.

The identification of risk factors is a very promising area for research, since prevention measures should be aimed at their elimination. As a preventive measure, early castration of animals that are not planned for breeding is proposed.

We have noted one more feature. The size of neoplasms detected at the age of 4 years, as a rule, did not exceed T1 - T2 according to the TNM classification [10,11,12]. Tumor sizes within T2-T4, and in some cases T4a-d, prevailed in animals older than 7 years.

\section{Conclusions}

The data obtained allow us to say with confidence that in our practice, breast tumors in dogs are found in almost one third of cases of all cancer patients among dogs, and account for $28 \%$. Among this number, females are in the lead, their percentage is $-98 \%$. In males, a breast tumor is not so common; it takes 4 th place and is $1.3 \%$. We also proved that the main percentage of mammary gland tumors of $56 \%$ occurs over 11 years of age, and at this age, most often the tumor has a size of T2-N4, in contrast to younger animals [8]. In noncastrated females, the percentage of breast tumors is more than 2 times higher. All these data allow us to conclude that it is necessary to develop approaches to early diagnosis of mammary gland neoplasms in pets and to actively popularize preventive measures, as well as to prescribe reasonable treatment, which at the moment can save or significantly prolong the life of an animal with a breast tumor [13-15].

\section{Reference}

1. M.N. Yakunina, E.M. Treschalina, A.A. Shimshirt Analysis of the incidence and clinical morphological characteristics of breast cancer of dogs and cats Veterinary Medicine,3-4, 21-23 (2010)

2. M.N. Yakunina, E.M. Treshchalina Systemic chemotherapy with taxotere versus intrapleural chemotherapy with cyclophosphamide for neoplastic pleurisy of cats, Russian Biotherapeutic Journal, 2, 85(2010) 
3. M.N. Yakunina, E.M. Treshchalina "Results of a prospective study and retrospective analysis of the efficacy of adjuvant chemotherapy with doxorubicin for spontaneous canine and feline breast cancer" RVZh, 4, 23-27 (2009)

4. M.N. Yakunina, V. A. Golubeva, D. V. Garanin Breast cancer of dogs and cats. Collective monograph, 79(2010).

5. M. N. Yakunina Complex treatment for spontaneous stage III dogs' breast cancer, Veterinary Medicine, 3, 52-54 (2011)

6. D. V. Fomicheva, S. V. Timofeev, E. M. Treschalina Features of metastasis of cats' breast cancer, Russian veterinary journal. Small pets, 2, 30-33 (2007)

7. M. S. Kalishyan, L.A. Sedakova, N. V. Andronova Possibilities of carrying out neoadjuvant polychemotherapy for canine breast cancer using the teraphthal + ascorbic acid catalytic system RBZh, 6, 1, 33. (2007)

8. M. S. Kalishyan, M. N. Yakunina, E. M. Treshchalina "Comparative analysis of spontaneous malignant tumors of the mammary gland of dogs and humans. Approaches to neoadjuvant chemotherapy ", 2, 41-44, 3, $42-43$ (2009)

9. M. S. Kalishyan, M. N. Yakunina, E. M. Treshchalina Comparative analysis of spontaneous malignant tumors of the mammary gland of dogs and humans. Approaches to neoadjuvant chemotherapy, Part 1 Russian veterinary journal. Small pets, 2, 41-44 (2009)

10. M. S. Kalishyan, L. A. Sedakova, N. V. Andronova Possibilities of carrying out neoadjuvant polychemotherapy for canine breast cancer using the teraphthal + ascorbic acid catalytic system RBZh, 6, 1, 33. (2007)

11. N. Stratmann, K. Failing, A. Richter Mamary tumor recurrence in bitches after regionl mastectomy. Vet Surg Jan. 37(1), 82-6 (2002)

12. D. Simon, D. Schoenrock, W. Baumg rtner, Nolte I. «Postoperative adjuvant treatment of invasive malignant mammary gland tumors in dogs with doxorubicin and docetaxel.», J Vet Intern Med. 20(5), 1184-90 (2006)

13. B. Overley, F. Shofer, M. Goldschmidt, D. Sherer, K. Sorenmo Association between ovariohysterectomy and feline mammary carcinoma $J$ Vet Intern Med, 19 (4), 560-3. PMID 16095174 (2005).

14. S.C. Chang, C.C. Chang, T.J. Chang Prognostic factors associated with survival two years after surgery in dogs with malignant mammary tumors: 79 cases (1998-2002). JAVMA 2005;227(10):1625-1630.

15. S.C. Chang, C.C. Chang, T.J. Chang Prognostic factors associated with survival two years after surgery in dogs with malignant mammary tumors: 79 cases (1998-2002). JAVMA, 227, 10. 1625- 1630 (2005) 